\title{
Study on Kinetics and Reaction Parameters of Biodiesel Production from Sunflower Oil and Methanol Using Zinc Oxide Supported Calcium Oxide
}

\author{
Oguzhan Illgen ${ }^{1 *}$ \\ ${ }^{1}$ Chemical Engineering Department, Engineering Faculty, Kocaeli University, 41380 Izmit-Kocaeli, Umuttepe Campus, Turkey \\ * Corresponding author, e-mail: oilgen@kocaeli.edu.tr
}

Received: 02 September 2021, Accepted: 18 November 2021, Published online: 27 January 2022

\begin{abstract}
This study investigated the effect of reaction parameter, reaction kinetics and mechanism of transesterification of sunflower oil with methanol by using $\mathrm{CaO} / \mathrm{ZnO}$ heterogeneous catalyst. The influence of reaction time, molar ratio and catalyst amount and reaction temperature on fatty acid methyl esters (FAME) yield was investigated. The catalysts were prepared by incipient wetness impregnation and characterized by using X-ray diffraction (XRD) and Hammett indicator method. The FAME contents were analyzed by gas chromatography using the EN 14103 standard method. The highest FAME yield of 82\% was obtained at 9/1 methanol/oil molar ratio, 3 wt.\% catalyst amount and 3 hours of reaction time at $65{ }^{\circ} \mathrm{C}$ of reaction temperature by using $20 \% \mathrm{CaO} / \mathrm{ZnO}$ catalyst. The reaction could be considered pseudo first order with respect to triglyceride (TG). The reaction model based on Eley-Rideal mechanism was proposed where adsorbed methanol reacted with TG before desorption of glycerin. The results showed that experimental reaction rates exhibited good agreement with calculated reaction rates.
\end{abstract}

Keywords

biodiesel, heterogeneous catalyst, kinetics, mechanism, Eley-Rideal

\section{Introduction}

Biodiesel is also known as FAME become an alternative clean fuel to petroleum diesel which can be obtained from edible and non-edible vegetable oils, waste vegetable oils, and animal fats [1]. Sunflower oil is the leading primary raw material, which is beneficial for biodiesel production with the advantage of not only high conversion of pure TGs to FAME, but also relatively short reaction time. The sustainable production trends of sunflower oil indicate that it can be used for both food and biodiesel production [2]. The triglycerides react with alcohol like methanol or ethanol in the presence of a basic catalysts like sodium hydroxide and potassium hydroxide or acidic catalysts like sulfuric acid and hydrochloric acid to generate biodiesel [3]. The alkaline catalysts are frequently used on industrial scale because reaction is faster and proceed under reasonable reaction conditions. The reactants have to be anhydrous to stay away from soap formation when homogeneous alkaline catalysts are employed. The acid catalysts could be applied to produce biodiesel in case of water and free fatty acids (FFA) content in oils. Unrefined and waste vegetable oils which contain high FFA are potential feedstocks for biodiesel production. Slower reaction rate is one of the disadvantages of acidic catalysts $[4,5]$. The homogeneously catalyzed processes produce significant amount of waste water throughout neutralization of catalyst and purifying biodiesel [6]. In addition, glycerol byproduct is hard to purify and refine. The practice of heterogeneous catalysts in biodiesel synthesis simplifies these disabilities $[7,8]$. The catalytic activities of metal oxides were investigated alone and with other metal oxide supports for biodiesel production [9]. The use of calcium oxide $(\mathrm{CaO})$ has attracted special attention since it can be obtained natural and cheap sources. Recently, eggshell [10], waste mud crab shell [11], mollusk [12], oyster shell [13], and dolomite [8, 14-16] were studied as heterogeneous catalyst for biodiesel production. Solubility of $\mathrm{CaO}$ in alcohol makes it difficult to separate from reaction mixture. Zinc oxide $(\mathrm{ZnO})$ has no catalytic activity in biodiesel production reaction and also would be preferred as a support. $\mathrm{ZnO}$ is an inexpensive, reusable, environmentally 
friendly and commercially available catalyst widely used in catalytic reactions. It is also frequently used as a support material in catalysts obtained by impregnation of metal oxides [4]. In this work, calcium acetate $(\mathrm{CaAc})$ was used as $\mathrm{CaO}$ source. $\mathrm{CaAc}$ decomposes at temperatures between 380 and $400{ }^{\circ} \mathrm{C}$ into acetone $\left(\mathrm{CH}_{3} \mathrm{COCH}_{3}\right)$ and $\mathrm{CaCO}_{3}$ according to following reaction [17]:

$$
\mathrm{Ca}\left(\mathrm{CH}_{3} \mathrm{COO}\right)_{2} \rightarrow \mathrm{CaCO}_{3}+\mathrm{CH}_{3} \mathrm{COCH}_{3} \text {. }
$$

The kinetics of transesterification by using heterogeneous catalysts were generally investigated as pseudo-order reaction with considering overall reaction because of excessive methanol concentration assumed unchanged during the reaction [18]. Eley-Rideal and Langmuir-Hinshelwood models were also investigated by researchers [19-21] as like other heterogeneously catalyzed reactions which involves three familiar steps (adsorption, surface reaction and desorption). The five different kinetic models were investigated by Gholipour Zanjani et al. [20]. In their study, nonlinear $\alpha$-order kinetic model with respect to triglyceride found better than pseudo order, Eley-Rideal and Langmuir-Hinshelwood models for the transesterification of rapeseed oil with methanol by using $\mathrm{K}_{2} \mathrm{CO}_{3} / \mathrm{Al}_{2} \mathrm{O}_{3}$ catalyst. Risso et al. [19] proposed Eley-Rideal mechanism that assumed that methanol and glycerol were adsorbed. The surface reaction involved reaction of adsorbed methanol and triglyceride to produce non-adsorbed biodiesel and glycerol. In another study, among the different proposed Eley-Rideal and Langmuir-Hinshelwood models by Purwanto et al. [21], Eley-Rideal mechanism where the adsorbed methanol reacts with triglyceride to produce an adsorbed methyl ester and glycerol exhibited best fit to experimental data. The novelty of this work is to investigate the effect of reaction parameters and describe the reaction kinetics and mechanism of transesterification of sunflower oil with methanol in presence of $\mathrm{CaO} / \mathrm{ZnO}$ heterogeneous catalyst.

In present study the impact of reaction time, molar ratio, catalyst amount and reaction temperature were investigated for transesterification of sunflower oil with methanol by using prepared $\mathrm{CaO} / \mathrm{ZnO}$ catalysts. The pseudo order kinetic models and reaction mechanism were also investigated.

\section{Experimental}

\subsection{Materials}

Edible grade sunflower oil was purchased from local market. The FFA content of sunflower oil determined as 0.2 wt.\% according to AOCS Official Method Cd 3a-63. Analytical grade methanol (99.5\%), $\mathrm{ZnO}, \mathrm{CaAc}$ and Hammett indicators (bromothymol blue, phenolphthalein, 2,4-dinitroaniline and 4-nitroaniline) were obtained from Merck. Analytical grade methyl heptadecanoate (99.5\%) which was used as internal standard obtained from Sigma Aldrich.

\subsection{Catalyst preparation}

The $\mathrm{CaO}$ was obtained from $\mathrm{CaAC}$ which was loaded on $\mathrm{ZnO}$. The $10 \% \mathrm{CaO} / \mathrm{ZnO}$ and $20 \% \mathrm{CaO} / \mathrm{ZnO}$ catalysts were prepared by incipient wetness impregnation of $\mathrm{ZnO}$ with an aqueous solution of $\mathrm{CaAc}$. The five grams of catalyst was prepared in each batch and contained $\mathrm{x} \% \mathrm{CaO}$ and the remaining amount of $\mathrm{ZnO}$. The required amount of $\mathrm{CaAC}$ to contain $10 \%$ or $20 \%$ percent $\mathrm{CaO}$ is dissolved in water equal to the water absorption capacity of the $\mathrm{ZnO}$. The prepared $\mathrm{CaAC}$ aqueous solution was added dropwise on the $\mathrm{ZnO}$ which was placed in the flask in an ultrasonic water bath at room temperature. The catalysts were dried at $120^{\circ} \mathrm{C}$ in an oven overnight and calcined at $850{ }^{\circ} \mathrm{C}$ for $2 \mathrm{~h}$. The $10 \% \mathrm{CaO}$ and $20 \% \mathrm{CaO}$ are the mass percentages of $\mathrm{CaO}$ in prepared catalysts.

\subsection{Characterization of catalyst}

Powder XRD analysis of the catalyst was performed with a Rigaku D/MAX 2200 X-ray diffractometer by using $\mathrm{CuK} \alpha$ radiation at rate of 0.02 over the 2-theta range of $10-80$. The base strength of the catalysts was determined by using Hammett indicators (H_s) by using the method described in literature [22]. Bromothymol blue $\left(\mathrm{H}_{-}=7.2\right)$, phenolphthalein $\left(\mathrm{H}_{-}=9.8\right), 2$, 4 -dinitroaniline $\left(\mathrm{H}_{-}=15\right)$ and 4-nitroaniline $\left(\mathrm{H}_{-}=18.4\right)$ were used as Hammett indicators.

\subsection{Transesterification reaction}

The reaction performances of the prepared catalysts were observed for the transesterification of sunflower oil and methanol. The reactions were performed in a $250 \mathrm{~mL}$ three-necked flask equipped with a condenser. After the reactor was loaded with different amounts methanol and catalyst, $50 \mathrm{~g}$ of sunflower oil was charged into the reactor. The catalyst was filtrated at the end of the reaction. The FAME content was measured by gas chromatography according to European regulated procedure EN 14103 [23]. Methyl heptadecanoate was used as an internal standard. The FAME yield (\%) was calculated using Eq. (2):

$\operatorname{FAME} \operatorname{yield}(\%)=\frac{\left(\sum A\right)-A_{E I}}{A_{E I}} \times \frac{C_{E I} \times V_{E I}}{m} \times 100$, 
where $\sum A$ is the total peak area from methyl esters, $A_{E I}$ is the peak area of internal standard, $C_{E I}\left(\mathrm{mg} \mathrm{mL}^{-1}\right)$ is the concentration of internal standard solution, $V_{E I}(\mathrm{~mL})$ is the volume of internal standard solution and $\mathrm{m}(\mathrm{mg})$ is the mass of sample.

In order to investigate the effect of the external mass transfer resistances during the reaction, reactions were performed with different stirring rates of 250, 500, 750 and $1000 \mathrm{rpm}$. The effect external diffusion was neglected because of same FAME yield obtained under 3 different stirring rates of 500, 750 and $1000 \mathrm{rpm}$. All experiments were carried out with a stirring rate of $750 \mathrm{rpm}$. The internal diffusion limitations were accepted negligible because of very small particle size of catalyst ( $<120 \mathrm{mesh})$ that used in slurry reactors [24].

\section{Results and discussion}

\subsection{Catalysts characterization}

The XRD patterns of $\mathrm{CaO} / \mathrm{ZnO}$ was presented in Fig. 1. The XRD pattern of $\mathrm{ZnO}$ exhibited at 2-theta $31.73^{\circ}, 34.41^{\circ}$, $36.23^{\circ}, 47.53^{\circ}, 56.53^{\circ}, 62.81^{\circ}, 66.32^{\circ}, 67.90^{\circ}, 69.02^{\circ}, 72.53^{\circ}$ and $76.90^{\circ}$, which corresponds to hexagonal zincite structure (JCPDS pattern 01-075-7917) [25, 26]. As depicted in Fig. 1, the XRD patterns of $\mathrm{CaO}$ peaks appeared at 2-theta value of $37.34^{\circ}, 53.82^{\circ}, 64.11^{\circ}$ and $67.35^{\circ}$ (JCPDS pattern 01-082-1691) [25-28].

The base strength of $\mathrm{ZnO}$ was observed in the range of $7.2<\mathrm{H}_{-}<9.8$. The highest base strength was observed after $\mathrm{CaO}$ loaded on $\mathrm{ZnO}$. The base strength increased to $15<\mathrm{H}_{-}<18.4$ for $\mathrm{CaO} / \mathrm{ZnO}$ catalysts. According to literature, base strength of the catalyst affects the activity for transesterification reaction. When catalytic activity and base strength are considered together, it is seen that the catalytic activity is related to the base strength of the catalyst. It was observed that higher reaction efficiency was obtained with higher base strength [22]. As mentioned previously, $\mathrm{ZnO}$ has no catalytic activity in biodiesel production reaction.

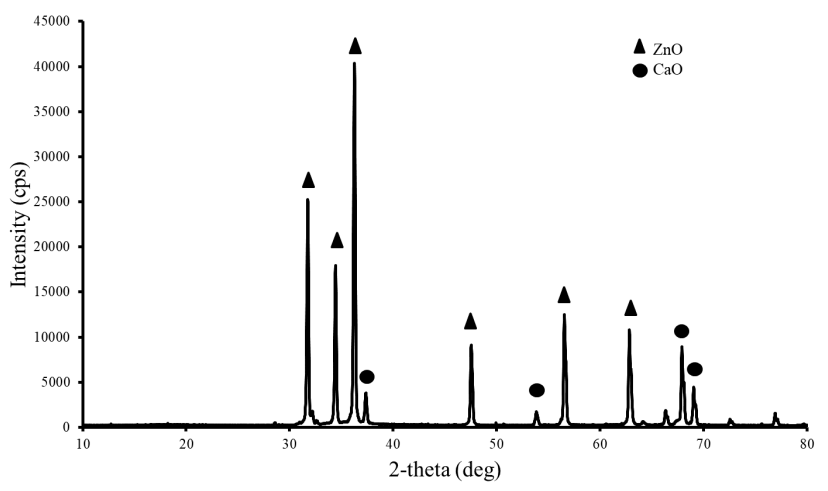

Fig. 1 XRD pattern of $\mathrm{CaO} / \mathrm{ZnO}$ catalyst

\subsection{Effect of reaction parameters}

\subsubsection{Effect of reaction time and molar ratio}

The reaction time and molar ratio of methanol to oil are directly affecting the cost of the process. In order to determine the equilibrium time of reaction, effect of reaction time on two different molar ratios (6:1 and 9:1) of methanol to oil were investigated firstly before the investigating effect of other reaction parameters. According to literature [29], 6:1 and 9:1 are frequently found suitable molar ratios in biodiesel production that are compatible with cost effective biodiesel production. As depicted in Fig. 2, FAME yield was increased with reaction time and reached equilibrium after 3 hours for 9:1 molar ratio and 4 hours for $6: 1$ molar ratio. The 3 hours of reaction time was preferred to investigate other reaction parameters. In order to consider clearly, effect of molar ratio was also investigated separately at constant reaction time of 3 hours.

Based on the stoichiometry of transesterification reaction three moles of alcohol are required for each mole of triglyceride. In order to drive the reaction to product side methanol was used in excess. In this study, apart from the stoichiometric ratio (3:1) four different mole ratios (6:1, 9:1, 12:1 and 15:1) were studied. As shown in Fig. 3, FAME yields increased up to mol ratio of 9:1 methanol to sunflower oil $(\sim 82 \%)$ and decreased at higher mole ratios in presence of $20 \% \mathrm{CaO} / \mathrm{ZnO}$ catalysts.

\subsubsection{Effect of catalyst amount}

When the amount of catalyst increases, it also increases the reaction rate. However, excessive amount of catalyst reduces the reaction yield due to mixing problems. In literature, supported $\mathrm{CaO}$ catalysts in biodiesel production

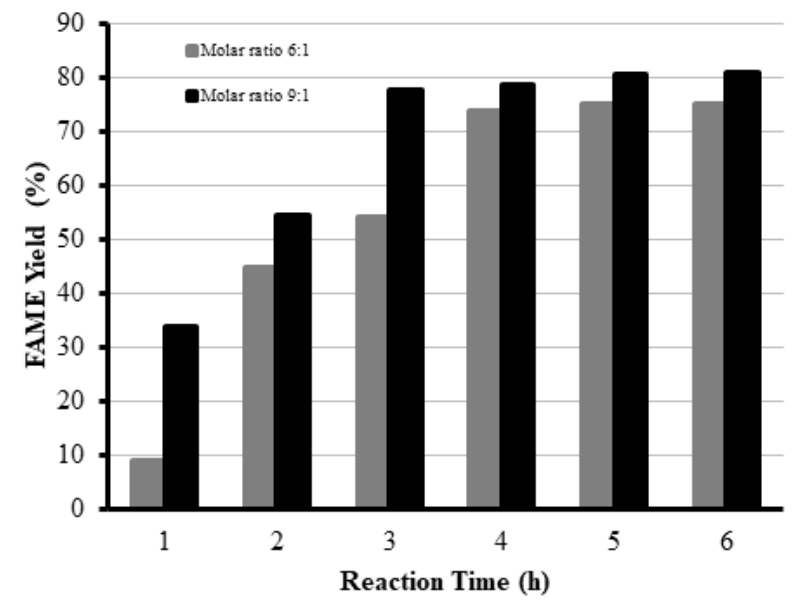

Fig. 2 Effect of reaction time on FAME yield. Reaction conditions: methanol/oil molar ratio 6:1 and 9:1; catalyst type $10 \% \mathrm{CaO} / \mathrm{ZnO}$; temperature $65^{\circ} \mathrm{C}$; catalyst amount $3 \%$ 
the catalyst amount was varied up to $12 \%$ [30]. In order to observe the effect of the catalyst amount on reaction yield, $10 \% \mathrm{CaO} / \mathrm{ZnO}$ and $20 \% \mathrm{CaO} / \mathrm{ZnO}$ catalysts were varied from $1.5 \%$ to $9 \%$ based on the oil weight. As shown in Fig. 4, FAME yields increased up to $3 \mathrm{wt} . \%$ and $4.5 \mathrm{wt} . \%$ catalyst amounts and remained constant for higher catalyst amounts in presence of $20 \% \mathrm{CaO} / \mathrm{ZnO}$ and $10 \% \mathrm{CaO} /$ $\mathrm{ZnO}$ catalysts, respectively. When reaction was performed by using $3 \% \mathrm{ZnO}$ catalyst under same reaction conditions, the FAME yield of less than $1 \%$ was observed. It can be clearly considered that $\mathrm{CaO}$ exhibits the catalytic activity for the reaction.

\subsubsection{Effect of temperature}

The temperature is one of the most important parameter that affects the rate of transesterification reaction. According to literature [30], the temperature was selected

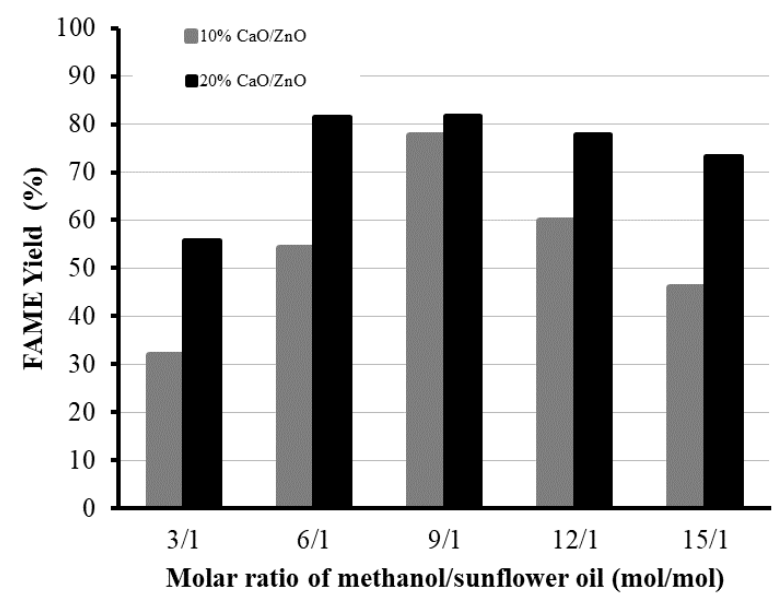

Fig. 3 Effect of mole ratio of methanol to sunflower oil on FAME yield. Reaction conditions: catalyst amount $3 \%$; temperature $65^{\circ} \mathrm{C}$; reaction time 3 hours

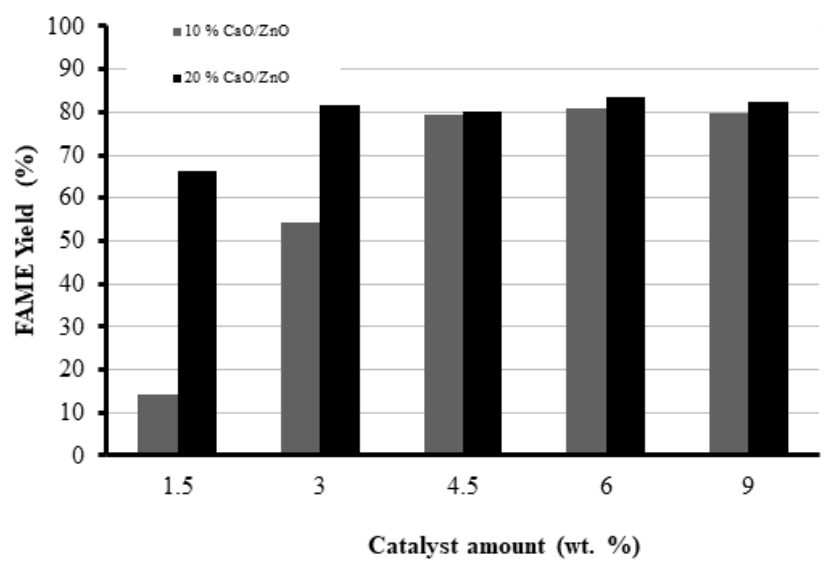

Fig. 4 Effect of catalyst amount of methanol to sunflower oil on FAME yield. Reaction conditions: methanol/oil molar ratio 6:1; temperature $65^{\circ} \mathrm{C}$; reaction time 3 hours around the boiling point of alcohol in order to obtain high biodiesel yield under atmospheric pressure. In current study, reaction temperatures of $50{ }^{\circ} \mathrm{C}, 60{ }^{\circ} \mathrm{C}$ and $65{ }^{\circ} \mathrm{C}$ were studied. Maximum temperature of the reaction was observed between $65^{\circ} \mathrm{C}$ and $67^{\circ} \mathrm{C}$ under atmospheric pressure, although the boiling point of methanol is $64.5^{\circ} \mathrm{C}$. As presented in Fig. 5, in presence of $10 \% \mathrm{CaO} /$ $\mathrm{ZnO}$ catalyst, low FAME yield was obtained at $50^{\circ} \mathrm{C}$ and FAME yield of around $55 \%$ was obtained at $60{ }^{\circ} \mathrm{C}$ and $65{ }^{\circ} \mathrm{C}$. Under the same reaction conditions, FAME yield of around $80 \%$ was observed at all studied temperatures when $20 \% \mathrm{CaO} / \mathrm{ZnO}$ catalysts were used.

\subsection{Reaction kinetics}

The biodiesel production reaction contains three successive reversible reaction steps where overall reaction can be summarized as:

$$
T G+3 \mathrm{MeOH} \leftrightarrow 3 B+G,
$$

where $T G$ : Triglyceride, $\mathrm{MeOH}$ : Methanol, B: Biodiesel and $G$ : Glycerol.

When higher than stoichiometric amount of methanol was used the irreversible non elementary reaction rate equation can be expressed as:

$$
\begin{aligned}
& -r_{T G}=\frac{N_{T G 0}}{W} \frac{d X_{T G}}{d t}=k C_{T G}^{\alpha} C_{\mathrm{MeOH}}^{\beta}, \\
& C_{T G}=C_{T G 0}\left(1-X_{T G}\right), \\
& C_{M}=C_{T G 0}\left(M-3 X_{T G}\right), \\
& M=\frac{C_{\mathrm{MeOH} 0}}{C_{T G 0}},
\end{aligned}
$$

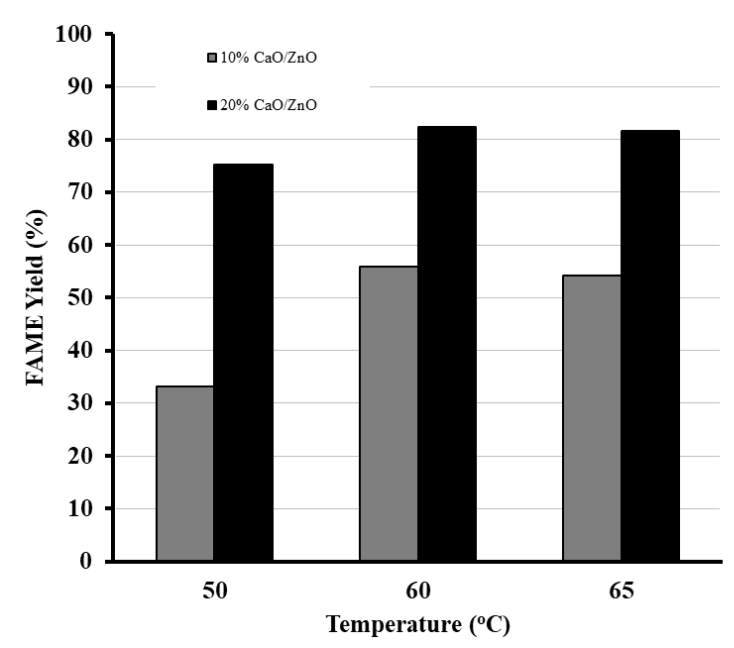

Fig. 5 Effect of temperature on FAME yield. Reaction conditions: methanol/oil molar ratio 6:1; catalyst amount $3 \%$; reaction time 3 hours 
where $k\left(L^{\alpha+\beta} / \mathrm{mol}^{\alpha+\beta-1}\right)$ (g cat. $\left.{ }^{-1} \mathrm{~min}^{-1}\right)$ is the reaction rate constant, $W(g)$ is catalyst weight, $\mathrm{N}_{\mathrm{TGO}}(\mathrm{mol}), \mathrm{X}_{\mathrm{TG}}$, $\mathrm{C}_{\mathrm{TG}}\left(\mathrm{mol} \mathrm{L}^{-1}\right)$ and $\mathrm{C}_{\mathrm{M}}\left(\mathrm{mol} \mathrm{L}^{-1}\right)$ are initial mole of $\mathrm{TG}$, conversion of TG, concentrations of $\mathrm{TG}$ and $\mathrm{MeOH}$, respectively, $\alpha$ and $\beta$ are the reaction orders with respect to TG and $\mathrm{MeOH}$, respectively.

The pseudo first order reaction rate equation was obtained by considering the reaction orders as $\alpha=1$ and $\beta=0$ in Eq. (4) and linear form could be expressed as:

$$
\frac{N_{T G 0}}{W} \ln \left(\frac{1}{1-X_{T G}}\right)=k C_{T G 0} t .
$$

The pseudo second order reaction rate equation was obtained by considering the reaction orders as $\alpha=1$ and $\beta=1$ in Eq. (4) and linear form could be expressed as:

$\frac{N_{T G 0}}{W(M-3)} \ln \left[\frac{M-3 X_{T G}}{\left(1-X_{T G}\right) M}\right]=k C_{T G 0}^{2} t$.

In Figs. 6 and 7, the $\mathrm{R}^{2}$ of pseudo order models are close to each other and they performed very good correlation. The $\mathrm{R}^{2}$ value performed slight decrease after the order of $\mathrm{MeOH}$ increased from zero to first while the reaction first

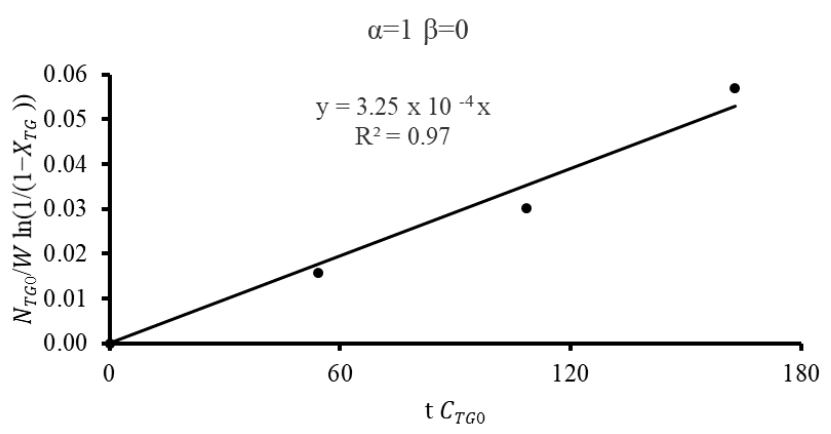

Fig. 6 Plot for pseudo first order reaction rate $(\alpha=1$ and $\beta=0)$.

Reaction conditions: methanol/oil molar ratio, 9:1; catalyst amount, 3\%; reaction time, 3 hours

$$
\alpha=1 \quad \beta=1
$$

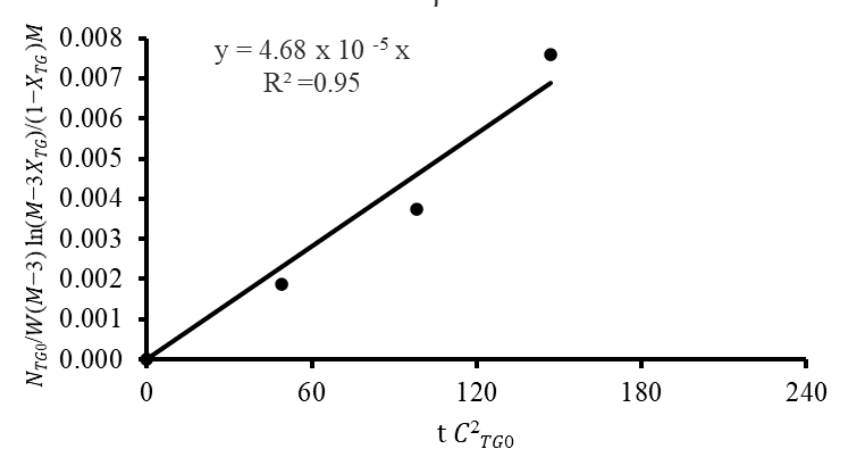

Fig. 7 Plot for pseudo first order reaction rate $(\alpha=1$ and $\beta=1)$. Reaction conditions: methanol/oil molar ratio, 9:1; catalyst amount, 3\%; reaction time, 3 hours order with respect to TG. The results of pseudo kinetic models showed that the reaction could be considered first order with respect to $\mathrm{TG}$ while independent from reaction order of $\mathrm{MeOH}$. According to literature, the reaction first order with respect to the TG when metal oxides used as heterogeneous catalyst [31].

The numerous kinetic studies were performed to investigate reaction conditions and mechanisms in presence of heterogeneous catalysts [18-22]. Since the reaction proceeds in liquid phase with solid catalyst the reaction steps were consisted of adsorption, surface reaction desorption. Eley-Rideal and Langmuir-Hinshelwood mechanisms are frequently researched to understand how transesterification reaction proceeds. The Eley-Rideal model was pervasively accepted to define reaction mechanism for heterogeneously catalyzed both esterification and transesterification reactions for biodiesel production [19, 21, 24, 32, 33]. The Eley-Rideal mechanism assumes that only one reactant adsorbed on the catalyst unlike the Langmuir-Hinshelwood mechanism that assumes both reactants adsorbed on catalyst surface. The proposed Eley-Rideal mechanisms for transesterification of triglyceride with methanol, the triglyceride reacts with adsorbed methanol during the surface reaction step. The acceptance of faster consumption of the intermediate products (monoglyceride and diglyceride) than triglyceride resulted acceptance of overall reaction. According to overall reaction, after the adsorption step(s), adsorbed methanol reacts with triglyceride or adsorbed triglyceride during the surface reaction step where biodiesel and glycerin produced.

In this study, the following Eley-Rideal model was considered in order to investigate reaction mechanism where the surface reaction was rate-limiting step [19-21].

$$
\begin{aligned}
& M+s \underset{k_{-M}}{\Leftrightarrow} M s \\
& T G+3 M s+s \rightarrow 3 B+G s+3 s, \\
& G s \underset{k_{-G}}{\Leftrightarrow} G+s, \\
& -r_{T G}=r_{S}=\frac{k K_{M}^{3} C_{M}^{3} C_{T G}}{\left(1+K_{M} C_{M}+K_{G} C_{G}\right)^{4}}\left(\mathrm{~mol} \mathrm{~g} \mathrm{cat.}^{-1} \mathrm{~min}^{-1}\right),
\end{aligned}
$$

where $M$ is methanol, $M_{s}$ is adsorbed methanol, $s$ is vacant cite, $B$ is biodiesel, $T G$ is triglyceride, $G s$ is adsorbed glycerol, $\mathrm{k}$ is rate constant, $K_{M}$ and $K_{G}$ are the adsorption constants. The constants were calculated via 
generalized reduced gradient (GRG) nonlinear method by using Microsoft Excel. The constants were determined after minimization of residual sum of squares (RSS) difference between experimental and calculated data. The rate constants were calculated as $k=1.29 \times 10^{-2}\left(\mathrm{~L} \mathrm{~g} \mathrm{cat.}^{-1}\right.$ $\left.\min ^{-1}\right), K_{M}=5.3968\left(\mathrm{~L} \mathrm{~mol}^{-1}\right)$ and $K_{G}=0.0257\left(\mathrm{~L} \mathrm{~mol}^{-1}\right)$.

As presented in Fig. 8, the $\mathrm{R}^{2}$ value of 0.94 was obtained for experimental and calculated reaction rates, which showed good agreement between experimental and proposed model.

The Eley-Rideal mechanism has been proposed in various studies for the biodiesel synthesis reaction with different heterogeneous catalysts. Risso et al. [19] proposed an Eley-Rideal type mechanism for methanolysis of soybean oil in presence of $\mathrm{CaO}$ catalyst. The model proposed in the study is almost identical to the model in this study, where the surface reaction involves the reaction of

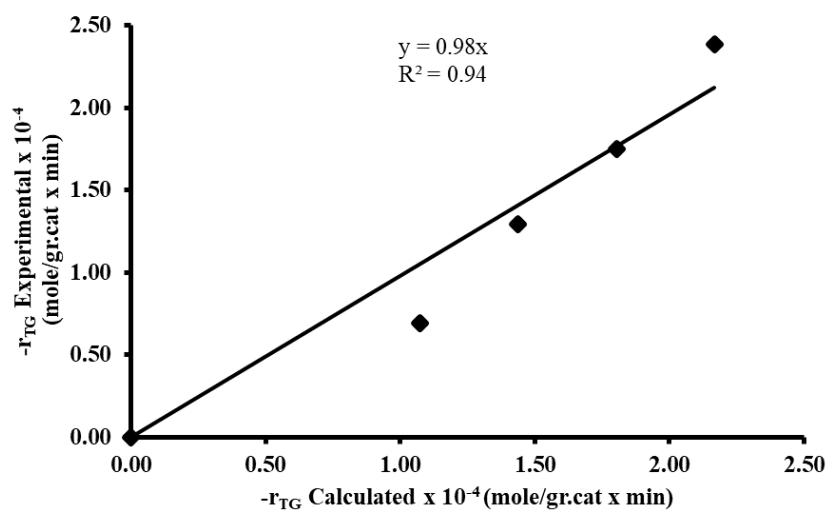

Fig. 8 Experimental versus calculated reaction rates based on suggested Eley-Rideal mechanism

\section{References}

[1] Agarwal, A. K. "Biofuels (alcohols and biodiesel) applications as fuels for internal combustion engines", Progress in Energy and Combustion Science, 33(3), pp. 233-271, 2007.

https://doi.org/10.1016/j.pecs.2006.08.003

[2] John, M., Abdullah, M. O., Hua, T. Y., Nolasco-Hipólito, C. "Techno-economical and energy analysis of sunflower oil biodiesel synthesis assisted with waste ginger leaves derived catalysts", Renewable Energy, 168, pp. 815-828, 2021.

https://doi.org/10.1016/j.renene.2020.12.100

[3] Karavalakis, G., Stournas, S., Karonis, D. "Evaluation of the oxidation stability of diesel/biodiesel blends", Fuel, 89(8), pp. 24832489, 2010.

https://doi.org/10.1016/j.fuel.2010.03.041

[4] Alba-Rubio, A. C., Santamaría-González, J., Mérida-Robles, J. M., Moreno-Tost, R., Martín-Alonso, D., Jiménez-López, A., MairelesTorres, P. "Heterogeneous transesterification processes by using $\mathrm{CaO}$ supported on zinc oxide as basic catalysts", Catalysis Today, 149(3-4), pp. 281-287, 2010.

https://doi.org/10.1016/j.cattod.2009.06.024 adsorbed methanol and triglycerides to produce non-adsorbed biodiesel and glycerol. Purwanto et al. [21] studied transesterification of soybean oil and methanol by using $\mathrm{K}_{2} \mathrm{O} / \mathrm{CaO}-\mathrm{ZnO}$ catalyst on the hybrid catalytic-plasma reactor and suggested very similar Eley-Rideal model with some minor differences. Their suggested model include the adsorbed methanol reacted with triglycerides to produce an adsorbed FAME and glycerol in bulk phase. Similarly, in another study by Wu et al. [24], the Eley-Rideal mechanism was proposed for the transesterification of canola oil with methanol in the presence of mesoporous alumina supported potassium catalyst. It is suggested that the reaction starts with methanol adsorption at the active sites of catalyst and followed by surface reaction between adsorbed methanol and triglyceride to obtain FAME and glycerol.

\section{Conclusions}

$\mathrm{CaO} / \mathrm{ZnO}$ catalyst has been evaluated for transesterification of sunflower oil with methanol. The FAME yield of $82 \%$ was achieved at $65^{\circ} \mathrm{C}$, with a 9:1 molar ratio of methanol to sunflower oil and catalyst amount of $3 \mathrm{wt} . \%$ after $3 \mathrm{~h}$ of reaction time by using $20 \% \mathrm{CaO} / \mathrm{ZnO}$ catalyst. The pseudo order kinetic models showed that the reaction first order with respect to the TG. The reaction was considered to follow Eley-Rideal mechanism where the surface reaction was rate-limiting step. The reaction rate equation found as:

$$
-r_{T G}=\frac{\left(1.29 \times 10^{-2}\right)\left(5.3968^{3}\right) C_{M}^{3} C_{T G}}{\left(1+5.3968 C_{M}+0.0257 C_{G}\right)^{4}}\left(\mathrm{~mol} \mathrm{~g} \mathrm{cat.}{ }^{-1} \mathrm{~min}^{-1}\right) \text {. }
$$

[5] Kulkarni, M. G., Dalai, A. K. "Waste Cooking Oil - An Economical Source for Biodiesel: A Review", Industrial \& Engineering Chemistry Research, 45(9), pp. 2901-2913, 2006.

https://oi.org/10.1021/ie0510526

[6] Kim, H.-J., Kang, B.-S., Kim, M.-J., Park, Y. M., Kim, D.-K., Lee, J.-S., Lee, K.-Y. "Transesterification of vegetable oil to biodiesel using heterogeneous base catalyst", Catalysis Today, 93-95, pp. 315-320, 2004.

https://doi.org/10.1016/j.cattod.2004.06.007

[7] Liu, X., Piao, X., Wang, Y., Zhu, S. "Calcium Ethoxide as a Solid Base Catalyst for the Transesterification of Soybean Oil to Biodiesel", Energy and Fuels, 22(2), pp. 1313-1317, 2008. https://doi.org/10.1021/ef700518h

[8] Çakırca, E. E., Tekin, G. N., İlgen, O., Akın, A. N. "Catalytic activity of $\mathrm{CaO}$-based catalyst in transesterification of microalgae oil with methanol", Energy \& Environment, 30(1), pp. 176-187, 2019.

https://doi.org/10.1177/0958305X18787317 
[9] Liang, X., Gao, S., Wu, H., Yang, J. "Highly efficient procedure for the synthesis of biodiesel from soybean oil", Fuel Processing Technology, 90(5), pp. 701-704, 2009.

https://doi.org/10.1016/j.fuproc.2008.12.012

[10] Wei, Z., Xu, C., Li, B. "Application of waste eggshell as low-cost solid catalyst for biodiesel production", Bioresource Technology, 100(11), pp. 2883-2885, 2009.

https://doi.org/10.1016/j.biortech.2008.12.039

[11] Boey, P-.L., Maniam, G. P., Hamid, S. A. "Biodiesel production via transesterification of palm olein using waste mud crab (Scylla serrata) shell as a heterogeneous catalyst", Bioresource Technology, 100(24), pp. 6362-6368, 2009.

https://doi.org/10.1016/j.biortech.2009.07.036

[12] Viriya-empikul, N., Krasae, P., Puttasawat, B., Yoosuk, B., Chollacoop, N., Faungnawakij, K. "Waste shells of mollusk and egg as biodiesel production catalysts", Bioresource Technology, 101(10), pp. 3765-3767, 2010.

https://doi.org/10.1016/j.biortech.2009.12.079

[13] Nakatani, N., Takamori, H., Takeda, K., Sakugawa, H. "Transesterification of soybean oil using combusted oyster shell waste as a catalyst", Bioresource Technology, 100(3), pp. 1510-1513, 2009. https://doi.org/10.1016/j.biortech.2008.09.007

[14] Ngamcharussrivichai,C.,Nunthasanti,P., Tanachai,S.,Bunyakiat,K. "Biodiesel production through transesterification over natural calciums", Fuel Processing Technology, 91(11), pp. 1409-1415, 2010. https://doi.org/10.1016/j.fuproc.2010.05.014

[15] Ilgen, O. "Dolomite as a heterogeneous catalyst for transesterification of canola oil", Fuel Processing Technology, 92(3), pp. 452455, 2011.

https://doi.org/10.1016/j.fuproc.2010.10.009

[16] Wilson, K., Hardacre, C., Lee, A. F., Montero, J. M., Shellard, L. "The application of calcined natural dolomitic rock as a solid base catalyst in triglyceride transesterification for biodiesel synthesis", Green Chemistry, 10(6), pp. 654-665, 2008. https://doi.org/10.1039/b800455b

[17] Adánez, J., de Diego, L. F., García-Labiano, F. "Calcination of calcium acetate and calcium magnesium acetate: effect of the reacting atmosphere", Fuel, 78(5), pp. 583-592, 1999.

https://doi.org/10.1016/S0016-2361(98)00186-0

[18] Ahmad Farid, M. A., Hassan, M. A., Taufiq-Yap, Y. H., Ibrahim, M. L., Hasan, M. Y., Ali, A. A. M., Othman, M. R., Shirai, Y. "Kinetic and thermodynamic of heterogeneously K3PO4/AC-catalysed transesterification via pseudo-first order mechanism and EyringPolanyi equation", Fuel, 232, pp. 653-658, 2018. https://doi.org/10.1016/j.fuel.2018.06.029

[19] Risso, R., Ferraz, P., Meireles, S., Fonseca, I., Vital, J. "Highly active Cao catalysts from waste shells of egg, oyster and clam for biodiesel production", Applied Catalyst A: General, 567, pp. 56-64, 2018.

https://doi.org/10.1016/j.apcata.2018.09.003

[20] Gholipour Zanjani, N., Kamran Pirzaman, A., Yazdanian, E. "Biodiesel production in the presence of heterogeneous catalyst of alumina: Study of kinetics and thermodynamics", International Journal of Chemical Kinetics, 52(7), pp. 472-484, 2020. https://doi.org/10.1002/kin.21363
[21] Purwanto, P., Buchori, L., Istadi, I. "Reaction rate law model and reaction mechanism covering effect of plasma role on the transesterification of triglyceride and methanol to biodiesel over a continuous flow hybrid catalytic-plasma reactor", Heliyon, 6(10), Article number: e05164, 2020.

https://doi.org/10.1016/j.heliyon.2020.e05164

[22] Xie, W., Li, H. "Alumina-supported potassium iodide as a heterogeneous catalyst for biodiesel production from soybean oil", Journal of Molecular Catalysis A: Chemical, 255(1-2), pp. 1-9, 2006.

https://doi.org/10.1016/j.molcata.2006.03.061

[23] European Committee for Standardization "EN14103 Fat and Oil Derivatives - Fatty Acid Methyl Esters (FAME) - Determination of Ester and Linolenic Acid Methyl Ester Content", European Committee for Standarization, Brussels, Belgium, 2011.

[24] Wu, W., Zhu, M., Zhang, D. "An experimental and kinetic study of canola oil transesterification catalyzed by mesoporous alumina supported potassium" Applied Catalysis A: General, 530, pp. 166173, 2017. https://doi.org/10.1016/j.apcata.2016.11.029

[25] Ansari, S., Ansari, M. S., Satsangee, S.P., Jain, R. " $\mathrm{Bi}_{2} \mathrm{O}_{3} / \mathrm{ZnO}$ nanocomposite: Synthesis, characterizations and its application in electrochemical detection of balofloxacin as an anti-biotic drug", Journal of Pharmaceutical Analysis, 11(1), pp. 57-67, 2021. https://doi.org/10.1016/j.jpha.2020.03.013

[26] Mansir, N., Teo, S. H., Mijan, N. A., Taufiq-Yap, Y. H. "Efficient reaction for biodiesel manufacturing using bi-functional oxide catalyst", Catalysis Communication, 149, Article number: 106201, 2021.

https://doi.org/10.1016/j.catcom.2020.106201

[27] Degfie, T. A., Mamo, T. T., Mekonnen, Y. S. "Optimized Biodiesel Production from Waste Cooking Oil (WCO) using Calcium Oxide (CaO) Nano-catalyst", Scientific Reports, 9(1), Article number: 18982, 2019.

https://doi.org/10.1038/s41598-019-55403-4

[28] Istadi, I., Prasetyo, S. A., Nugroho, T. S. "Characterization of $\mathrm{K}_{2} \mathrm{O} / \mathrm{CaO}-\mathrm{ZnO}$ Catalyst for Transesterification of Soybean Oil to Biodiesel", Procedia Environmental Sciences, 23, pp. 394-399, 2015.

https://doi.org/10.1016/j.proenv.2015.01.056

[29] Musa, I. A. "The effects of alcohol to oil molar ratios and the type of alcohol on biodiesel production using transesterification process", Egyptian Journal of Petroleum, 25(1), pp. 21-31, 2016. https://doi.org/10.1016/j.ejpe.2015.06.007

[30] Chozhavendhan, S., Vijay Pradhap Singh, M., Fransila, B., Praveen Kumar, R., Karthiga Devi, G. "A review on influencing parameters of biodiesel production and purification processes", Current Research in Green and Sustainable Chemistry, 1-2, pp. $1-6,2020$. https://doi.org/10.1016/j.crgsc.2020.04.002

[31] Nambo, A., Miralda, C. M., Jasinski, J. B., Carreon, M. A. "Methanolysis of olive oil for biodiesel synthesis over $\mathrm{ZnO}$ nanorods", Reaction Kinetics, Mechanisms and Catalysis, 114(2), pp. 583-595, 2015. https://doi.org/10.1007/s11144-014-0802-3 
[32] Ude, C. N., Onukwuli, O. D. "Kinetic modeling of transesterification of gmelina seed oil catalyzed by alkaline activated clay $(\mathrm{NaOH} / \mathrm{clay})$ catalyst", Reaction Kinetics, Mechanisms and Catalysis, 127(2), pp. 1039-1058, 2019.

https://doi.org/10.1007/s11144-019-01604-x
[33] Kapil, A., Wilson, K., Lee, A. F., Sadhukhan, J. "Kinetic Modeling Studies of Heterogeneously Catalyzed Biodiesel Synthesis Reactions", Industrial \& Engineering Chemistry Research, 50(9), pp. 4818-4830, 2011.

https://doi.org/10.1021/ie101403f 